\title{
Familial translocations involving 15q11-q13 can give rise to interstitial deletions causing Prader-Willi or Angelman syndrome
}

Bernhard Horsthemke, Anneke Maat-Kievit, Eva Sleegers, Ans van den Ouweland, Karin Buiting, Christina Lich, Paul Mollevanger, Geoff Beverstock, Gabriele Gillessen-Kaesbach, Gesa Schwanitz

Institut für

Humangenetik, Universitätsklinikum Essen,

Hufelandstrasse 55, D-45122 Essen,

Germany

B Horsthemke

K Buiting

C Lich

G Gillessen-Kaesbach

Klinisch Genetisch Centrum,

Leiden,

The Netherlands

A Maat-Kievit

Institut für

Humangenetik,

Universität Bonn,

Germany

E Sleegers

G Schwanitz

Department of

Clinical Genetics,

University Hospital

and Erasmus

University,

Rotterdam

The Netherlands

A van den Ouweland

Department of Clinical Cytogenetics, State University

Hospital,

Leiden,

The Netherlands

$P$ Mollevanger

G Beverstock

Correspondence to: Dr Horsthemke.

Received 28 March 1996 Revised version accepted for publication 14 May 1996

\begin{abstract}
A de novo interstitial deletion of 15q11-q13 is the major cause of Prader-Willi syndrome (PWS) and Angelman syndrome (AS). Here we describe two unrelated PWS patients with a typical deletion, whose fathers have a balanced translocation involving the PWS/AS region. Microsatellite data suggest that the deletion is the result of an unequal crossover between the derivative chromosome 15 and the normal chromosome 15 . We conclude that familial translocations involving 15q11-q13 can give rise to interstitial deletions causing PWS or AS and that prenatal diagnosis in such families should include fluorescence in situ hybridisation or microsatellite studies or both.

(f Med Genet 1996;33:848-851)
\end{abstract}

Key words: Prader-Willi syndrome; chromosome 15; translocation.

Prader-Willi syndrome (PWS) and Angelman syndrome (AS) are caused by the loss of function of imprinted genes in 15q11-q13. ${ }^{1}$ Approximately $70 \%$ of patients have a deletion of 15q11-q13, which in PWS is always of paternal origin and in AS always of maternal origin. Most deletions are de novo interstitial deletions, which probably arise by an unequal crossover between repeated DNA sequences flanking the PWS/AS region. ${ }^{23}$ In a few percent of cases, the deletion is the result of an unbalanced translocation. Unbalanced translocations can occur de novo or by segregation of chromosomes involved in a familial balanced translocation. ${ }^{4}$ Most PWS patients and a few AS patients without a deletion have two maternal or two paternal chromosomes 15, respectively. Uniparental disomy (UPD) most often results from the postzygotic correction of a meiotic non-disjunction event. ${ }^{5}$

Smeets et $a l^{6}$ described a family with a balanced translocation $\mathrm{t}(6 ; 15)(\mathrm{p} 25.3 ; \mathrm{q} 11.1)$, in which one cousin had PWS and another had AS. Cytogenetic and molecular studies showed that the PWS patient had a de novo deletion of $15 \mathrm{q} 12$ on the paternally derived derivative chromosome 6 and the AS patient had uniparental paternal heterodisomy for chromosome 15. Here we describe two unrelated families in which the father has a balanced translocation involving $15 \mathrm{q} 11-\mathrm{q} 13$. In both cases, a de novo interstitial deletion of 15q11-q13 occurred, which resulted in a child with PWS. The findings reported by Smeets et $a l^{6}$ and in this report show that familial translocations involving the PWS/AS region on chromosome 15 can give rise to interstitial deletions and uniparental disomy.

\section{Case reports}

FAMILY $S$ (GERMANY)

The proband (III.6) is the second child of young and unrelated parents (age of parents at birth, 29 years) (fig 1). Cytogenetic analysis was performed because of clinical signs of Down syndrome. Chromosome analysis showed trisomy 21 and a balanced translocation (karyotype $47, \mathrm{XY},+21, \mathrm{t}(15 ; 18)(\mathrm{q} 12 ; \mathrm{q} 12))$. The translocation was also present in the father (II.3) and the paternal grandfather (I.1) (karyotypes $46, \mathrm{XY}, \mathrm{t}(15 ; 18)(\mathrm{q} 12 ; \mathrm{q} 12))$. A metaphase of the father is shown in fig $2 \mathrm{~A}$. The first son (III.4) is healthy and no cytogenetic analysis was done. A second pregnancy resulted in an abortion (III.5). During the fourth pregnancy, which was uneventful apart from reduced fetal movements, a prenatal diagnosis was performed. Amniotic fluid cells indicated a normal male karyotype $(46, \mathrm{XY})$. Delivery was by caesarean section in the 38th week of pregnancy because of a pathological CTG. At birth, the boy (III.7) had a weight of $2420 \mathrm{~g}$ (10th centile), length $49 \mathrm{~cm}$ (50th centile), and head circumference $34 \mathrm{~cm}$ (50th centile). Pronounced muscular hypotonia, pale skin, high arched palate, abnormal EEG, and cryptorchidism were observed. Tube feeding was necessary for three months.

The father has two healthy sibs. His sister (II.1) has a normal female karyotype (46,XX). She had three abortions, which were not investigated cytogenetically. His brother (II.2) has not been investigated. He has no offspring. Their mother had one abortion in the first trimester. Sibs of the paternal grandfather (I.1) could not be investigated, but there are no signs of developmental retardation or PraderWilli syndrome.

FAMILY E (THE NETHERLANDS)

Cytogenetic analysis of a mentally retarded boy (III.1) and his normal father (II.2) showed a balanced translocation $(46, \mathrm{XY}, \mathrm{t}(8 ; 15)$ (q11.2; $\mathrm{q} 11.2 / \mathrm{q} 13)$. The karyotype of the boy is shown 
Family S

।

II

III

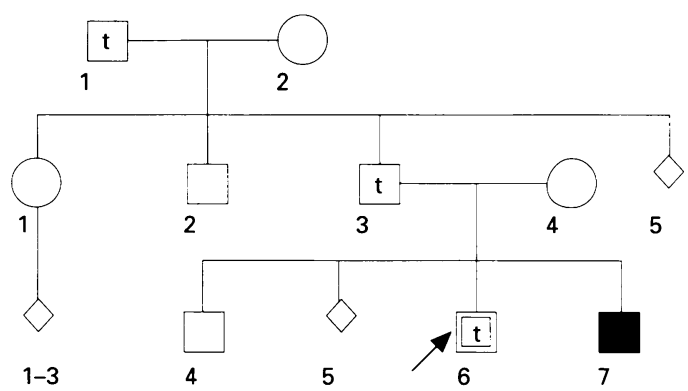

Family E

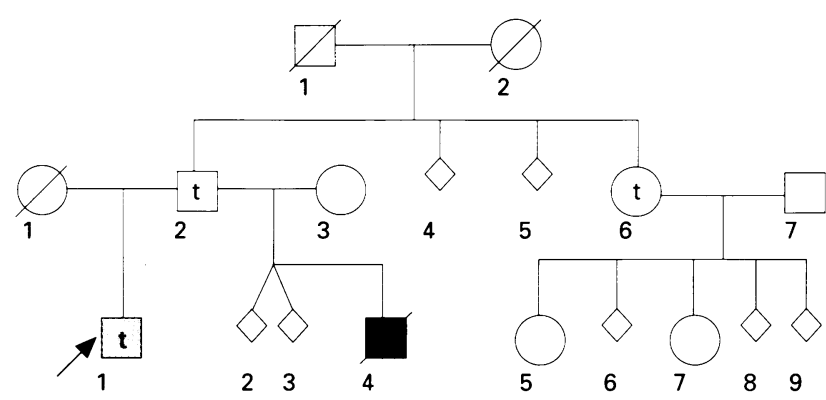

\begin{tabular}{l}
\hline $\mathrm{t}$ Translocation carrier \\
$\square$ Mental retardation \\
PWS \\
$\square$ Trisomy \\
\hline
\end{tabular}

Figure 1 Abbreviated pedigrees of families $S$ and $E$.

in fig $2 \mathrm{~B}$. The cause of the mental retardation is unknown. Pregnancy and birth were uneventful. He has no dysmorphic features or focal neurological signs. Metabolic studies were normal. Uniparental disomy 15 or a deletion 15q11-q13 were excluded by DNA analysis. The first pregnancy of a new relationship of this father, a twin pregnancy (III.2, III.3), ended in a miscarriage at 12 weeks' gestation. In the second pregnancy, amniocentesis was per-

A

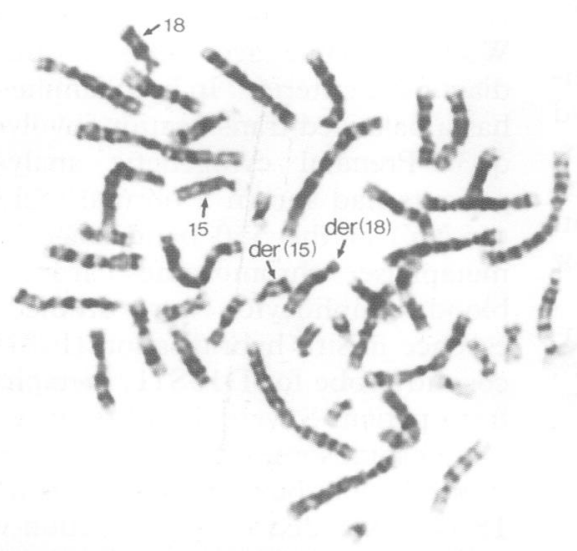

B
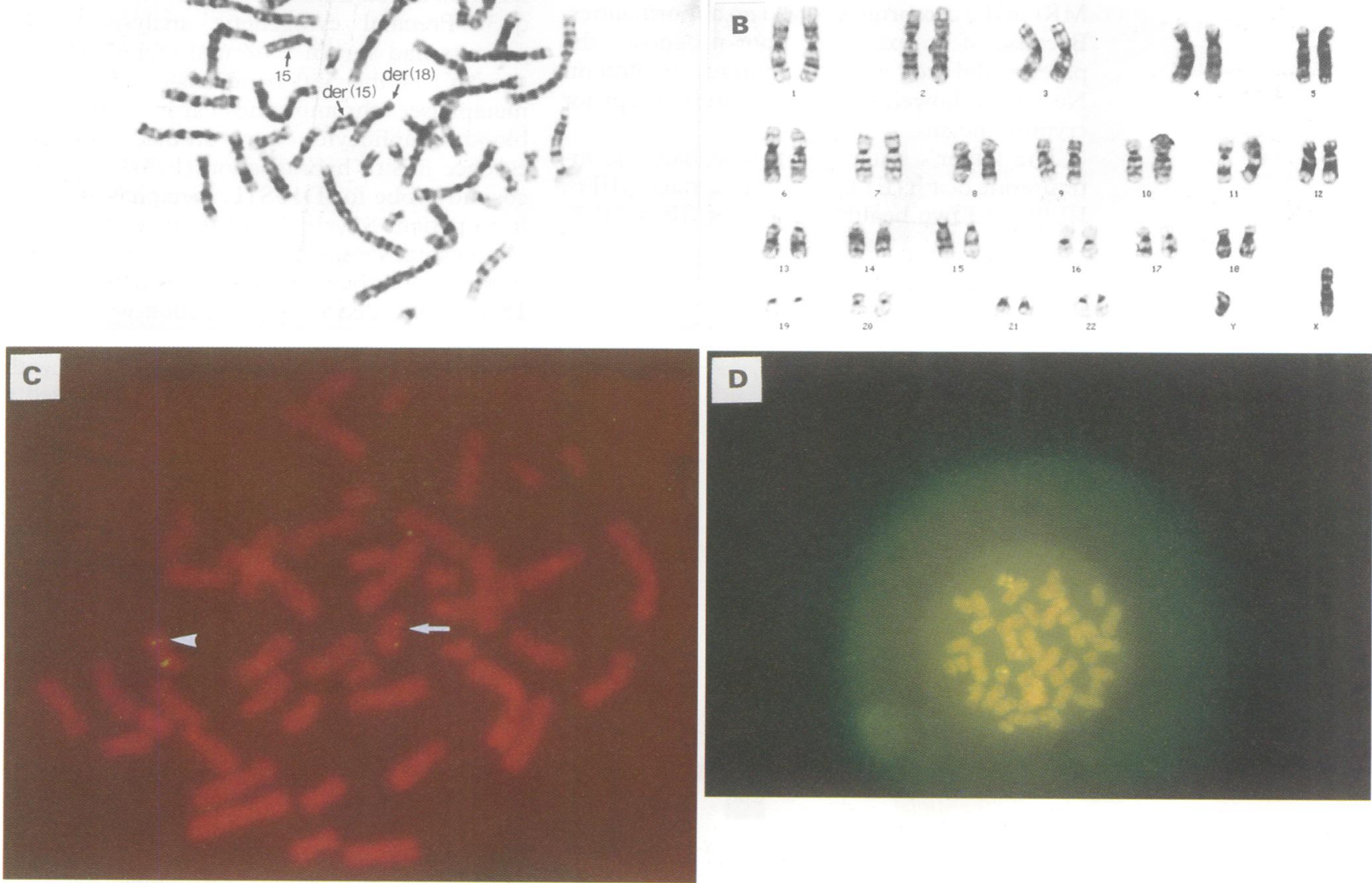

Figure 2 Cytogenetic analysis. (A) Metaphase of II.3 in family S. The normal and derivative chromosomes are indicated. (B) Karyotype of III. 1 in family E. (C) FISH analysis of the patient in family S. A probe for D15S11 showed a signal on one chromosome 15 (arrowhead), but not on the other (arrow). The PML probe gave a signal on both homologues. Chromosomes were counterstained with propidium iodide. (D) FISH analysis of the patient in family E. A probe for SNRPN showed a signal on one chromosome 15, but not on the other. The PML probe gave a signal on both homologues. 
Table 1 DNA analysis

\begin{tabular}{|c|c|c|c|c|c|c|c|c|}
\hline \multirow[b]{2}{*}{ DNA marker } & \multicolumn{4}{|c|}{ Family $E$} & \multicolumn{4}{|c|}{ Family $S$} \\
\hline & III. 1 & II. 2 & II. 3 & $I I I .4$ & III. 6 & II. 3 & $I I .4$ & III. 7 \\
\hline $\begin{array}{l}\text { D15S541 } \\
\text { D15S543 } \\
\text { D15S11 } \\
\text { D15S63 } \\
\text { D15S128 } \\
\text { GABRB3 } \\
\text { D15S144 } \\
\text { CYP19 }\end{array}$ & $\begin{array}{l}1,2 \\
2,1 \\
3,4 \\
\mathrm{~m}, \mathrm{p} \\
1,2 \\
2,4 \\
1,3 \\
1,3\end{array}$ & $\begin{array}{l}1,2 \\
1,1 \\
4,4 \\
\text { NT } \\
2,2 \\
1,4 \\
2,3 \\
2,3\end{array}$ & $\begin{array}{l}3,1 \\
2,2 \\
2,4 \\
\text { NT } \\
3,2 \\
3,4 \\
2,2 \\
1,3\end{array}$ & $\begin{array}{l}3,- \\
2,- \\
2,- \\
\text { m,- } \\
3,- \\
3,- \\
2,2 \\
3,3\end{array}$ & $\begin{array}{l}2,2 \\
2,1 \\
\text { NT } \\
\text { NT } \\
1,1 \\
2,1 \\
\text { NI } \\
2,1\end{array}$ & $\begin{array}{l}1,2 \\
3,1 \\
2,2 \\
\text { NT } \\
1,1 \\
3,1 \\
\text { NI } \\
2,1\end{array}$ & $\begin{array}{l}2,3 \\
2,1 \\
3,4 \\
\text { NT } \\
1,2 \\
2,1 \\
\text { NI } \\
2,2\end{array}$ & $\begin{array}{l}3,- \\
1,- \\
4,- \\
\mathrm{m},- \\
2,- \\
1,- \\
\mathrm{NI} \\
2,2\end{array}$ \\
\hline
\end{tabular}

m, maternal band; p, paternal band; NT, not tested; NI, not informative. Note that III.1 and III. 4 in family E are half brothers and that there is a recombination between D15S144 and CYP19 in III.4. formed, and normal chromosomes $(46, \mathrm{XY})$ were found. The child (III.4) was born at term with the aid of vacuum extraction because of bradycardia and meconicum in the amniotic fluid. The umbilical cord was short $(20 \mathrm{~cm})$ and torn off during birth. Apgar scores were 4, 5, and 7 after one, five, and 10 minutes, respectively. He showed severe hypotonia and respiratory insufficiency, and needed artificial ventilation. There was no pulmonary explanation for his respiratory distress, which did not improve in the following days. He also showed no sucking reflex and needed gavage feeding. His birth weight was $3265 \mathrm{~g}$ (40th centile) and his head circumference was $35.5 \mathrm{~cm}$ (50th centile). He had a small face with a narrow bitemporal diameter, hypertelorism, micrognathia, cryptorchidism, scrotal hypoplasia, contractures of the extremities, and simian creases of both hands. EEG, EMG, and MRI of the cerebrum showed no abnormalities. Because of an extremely poor prognosis, the parents did not wish to continue treatment. Necropsy showed no abnormalities except for cryptorchidism.

The father's sister (II.6), who had one intrauterine death (III.6), two miscarriages (III.8, III.9), and two healthy daughters (III.5, III.7) carries the same translocation.
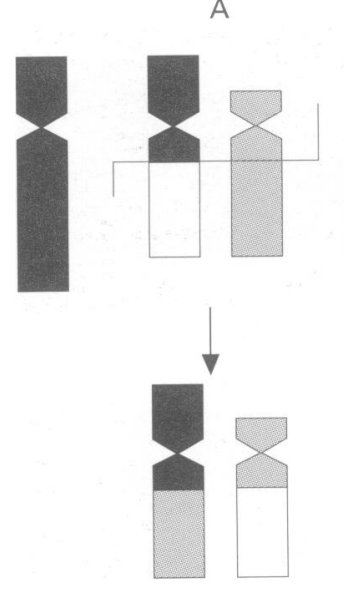

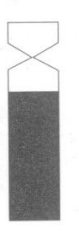

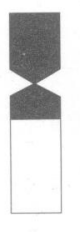
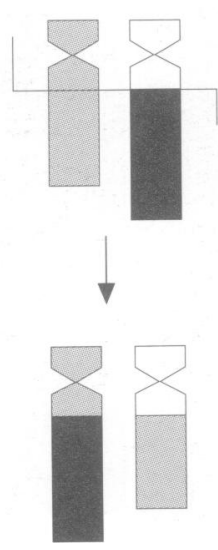

Figure 3 Possible crossover events between a normal chromosome 15 and a translocation chromosome in family E. Hatched chromosome, normal chromosome 15; white, translocated chromosome 15 material; black, chromosome 8 . A crossover between the der(8) and the normal chromosome 15 results in a chromosome 15 in which the telomeric part is derived from the translocation chromosome $(A)$. A crossover between the der $(15)$ and the normal chromosome 15 results in a chromosome 15 in which the telomeric part is derived from the normal homologue $(B)$. The data described in the text suggest that the crossovers are unequal and that mechanism $B$ occurred in families $E$ and $S$.

\section{Methods}

CYTOGENETIC ANALYSIS

Cytogenetic studies were carried out on QFQ and RBA banded chromosomes (550 bands) from cultured amniotic fluid cells and peripheral blood lymphocytes using standard methods. Fluorescence in situ hybridisation (FISH) with probes D15S11 and SNRPN was performed on metaphase spreads from peripheral blood lymphocytes according to the manufacturer's instructions (Oncor). The reagents also contain a marker (PML) that hybridises to specific sequences in $15 \mathrm{q} 22$ to facilitate the identification of both 15 homologues. In addition, we used library probes for chromosomes 15 and 18 to exclude cryptic translocations on the paternally derived chromosomes in family $S$.

\section{DNA ANALYSIS}

The methylation status of the D15S63 locus was determined by probing $B g l \mathrm{II}+C f o \mathrm{I}$ digested DNA with PW71B. ${ }^{78}$ The following DNA polymorphisms were studied: D15S11/ StyI, ${ }^{9}$ D15S541, ${ }^{10}$ D15S543, ${ }^{10}$ D15S128, ${ }^{11}$ GABRB3, ${ }^{12}$ D $15 S 144,{ }^{13}$ and CYP $19 .{ }^{14}$

\section{Results and discussion}

Subject III.7 in family $S$ (patient $S$ ) and subject III. 4 in family E (patient E) have typical PraderWilli syndrome according to the consensus diagnostic criteria. ${ }^{15}$ In both families, the father has a balanced translocation involving 15q11q13. Prenatal cytogenetic analysis of the patients had shown a normal male karyotype $(46, \mathrm{XY})$ at the 550 band stage. After birth, metaphase chromosomes from peripheral blood lymphocytes were studied by fluorescence in situ hybridisation (FISH). Using a cosmid probe for D15S11, metaphase spreads from patient $S$ were found to have a signal on one chromosome 15 only (fig 2C). A cryptic translocation between chromosomes 15 and 18 was excluded by hybridisation with library probes for these two chromosomes (not shown). Patient E was studied by FISH with a cosmid probe for SNRPN, which showed a deletion (fig 2D).

To determine the extent and origin of the deletions, we used the D15S63 methylation test and performed microsatellite analysis with five markers mapping within the typical PWS/ AS deletion region (D15S541, D15S543, D15S11, D15S128, and GABRB3) and two markers mapping to $15 \mathrm{q} 14-\mathrm{q} 21$ (D15S144 and CYP19). The results are summarised in table 1. Both patients lack paternal alleles from D15S541 to D15S128. Patient E also lacks a paternal allele at GABRB3. Patient $S$ is hemior homozygous at this locus. These data suggest that the patients have a typical deletion. As the fathers are heterozygous at these loci, the deletions have occurred de novo.

Although we cannot distinguish between hemizygosity and homozygosity for D15S144 and CYP19, the cytogenetic data exclude an involvement of these loci in the deletions. Hence, D15S144 is the most proximal intact 
and informative marker in family E. In family $\mathrm{S}$, this is CYP19 because D15S144 was not informative. The PWS patients and their translocation carrying brothers have different paternal alleles at these loci. Assuming that there is no recombination between the translocation breakpoint and D15S144 in the brother of patient E (III.1), allele 3 is on the derivative chromosome 8 and allele 2 is on the normal paternal chromosome 15 . In family $S$, allele 1 of CYP19 is on the derivative chromosome 18 and allele 2 is on the normal paternal chromosome, again assuming that there is no recombination between the translocation breakpoint and this marker in the brother of patient S (III.6). In both families, the patients inherited the alleles located on their father's normal chromosomes. This suggests that the deletions are the result of unequal crossovers between the derivative chromosomes 15 and the normal homologues (mechanism B in fig 3). It should be noted, however, that we do not know the linkage phase in these families. Therefore, mechanism A (fig 3) cannot be formally excluded.

In addition to our families and the family reported by Smeets et $a l,{ }^{6}$ we are aware of at least one other family in which a 15q11-q13 deletion occurred in a family segregating a familial translocation involving chromosome $15(\mathrm{t}(\mathrm{Y} ; 15)(\mathrm{q} 12 ; \mathrm{p} 11))$, although the translocation breakpoint in this family is outside the PWS/AS region (S Eliez, C DeLozier, personal communication). In the families identified by Smeets et $a l^{6}$ and Eliez and DeLozier, the deletion is present on a translocation chromosome. In our families, the deletion is present on an otherwise normal chromosome and was overlooked by conventional cytogenetic analysis. These findings show that interstitial deletions can occur de novo in families with a balanced translocation involving 15q11-q13. However, the number of families is too small to prove that translocations increase the frequency of unequal crossovers. Similarly, we do not know whether translocations involving other chromosomal regions will give rise to deletions at the same frequency as those involving 15q11-q13, or whether our findings are specific for chromosome 15 . The presence of DNA repeats flanking the PWS/AS region ${ }^{2}$ may support the latter view. However, there are several examples of families in which one translocation carrier is healthy and another one is affected. The disease may be related to a de novo submicroscopic deletion or the presence of uniparental disomy.

Our findings have important implications for prenatal diagnosis. It is common practice to exclude risk, when a fetus is found to have the same balanced translocation as his parents or to have a normal karyotype. At least for translocations involving $15 \mathrm{q} 11-\mathrm{q} 13$, this can be wrong. We conclude that prenatal diagnosis in such cases should include FISH and microsatellite analysis to rule out a deletion or uniparental disomy. Depending on the parental origin, such a defect leads to Prader-Willi or Angelman syndromes.

We wish to thank Dr S Schlensker for providing GTG banded slides of II. 3 in family S, and Professor E Passarge, Professor $H$ Galjaard, and Dr A van Haeringen for continuous interest. Part of this work was supported by the Deutsche Forschungsgemeinschaft.

1 Nicholls RD. Genomic imprinting and candidate genes in the Prader-Willi and Angelman syndromes. Curr Opin Genet Dev 1993;3:445-56.

2 Buiting K, Greger V, Brownstein B, et al. A putative gene family in 15q11-13 and 16p11.2: possible implications Acad Sci USA 1992;89:5457-61.

3 Kuwano A, Mutirangura A, Dittrich B, et al. Molecular dissection of the Prader-Willi/Angelman syndrome region dissection of the Prader-Willi/Angelman syndrome region
$(15 q 11-13)$ by YAC cloning and FISH analysis. Hum (15q11-13) by YAC cloning and FISH analysis.
Molec Genet 1992;1:417-25 (corrigendum, 1:784).

4 Hulten M, Armstrong S, Challinor P, et al. Genomic imprinting in an Angelman and Prader-Willi translocation family. Lancet 1991;338:638-9.

5 Ledbetter DH, Engel E. Uniparental disomy in humans: development of an imprinting map and its implications for prenatal diagnosis. Hum Molec Genet 1995;4:1757-64.

6 Smeets DFCM, Hamel BCJ, Nelen MR, et al. Prader-Willi syndrome and Angelman syndrome in cousins from a syndrome and Angelman syndrome in cousins from a family with a translocation between

7 Ditrich B, Robinson WP, Knoblauch $\mathrm{H}$, et al. Molecular diagnosis of the Prader-Willi and Angelman syndromes by detection of parent-of-origin specific DNA methylation in 15q11-13. Hum Genet 1992;90:313-15.

8 Dittrich B, Buiting K, Gross S, Horsthemke B. Characterization of a methylation imprint in the Prader-Willi syndrome region. Hum Molec Genet 1993;2:1995-9.

9 Hamabe J, Niikawa N. StyI polymorphism at the Di5S11 locus. Nucleic Acids Res 1990;18:5579.

10 Christian SL, Robinson WP, Huang B, et al. Molecular characterization of two proximal deletion breakpoint regions in Prader-Willi and Angelman syndrome patients. Am F Hum Genet 1995;57:40-8.

11 Beckmann JS, Tomfohrde J, Barnes RI, et al. A linkage map of human chromosome 15 with an average resolution of $2 \mathrm{cM}$ and containing 55 polymorphic microsatellites. Hum Molec Genet 1993;2:2019-30.

12 Mutirangura A, Greenberg F, Butler MG, et al. Multiplex PCR of three dinucleotide repeats in the Prader-Willi/
Angelman critical region (15q11-13): molecular diagnosis and mechanisms of uniparental disomy. Hum Molec Genet 1993;2:143-51

13 Gyapay G, Morisette J, Vignal A, et al. The 1993-94 Généthon human genetic linkage map. Nature Genet 1994;7: 246.

14 Polymeropopulos MH, Xiao H, Rath DS, Merril CR. Tetranucleotide repeat polymorphism at the human aromatase cytochrome P-450 gene (CYP19). Nucleic Acids Res 1991;19:195.

15 Holm VA, Cassidy SB, Butler MG, et al. Prader-Willi syndrome: consensus criteria. Pediatrics 1993;91:398-402. 